\title{
periferio
}

\section{EDUCAÇÃO NO SUBÚRBIO CARIOCA: SOCIABILIDADE E ORGANIZAÇÃO DOCENTE NA PRIMEIRA REPÚBLICA}

\author{
Marcelo Gomes da Silva ${ }^{1}$ \\ Universidade Federal Fluminense
}

\section{Resumo}

A ocupação do território da cidade do Rio de Janeiro passou por várias transformações no início do século XX. O deslocamento da população pobre para regiões mais afastadas do centro fez emergir demandas por transporte e escolarização. 0 presente trabalho tem por objetivo analisar algumas relações surgidas a partir do processo de estruturação educacional criado para suprir a demanda por instrução pública no subúrbio carioca. Neste sentido, a criação dos distritos escolares e a distribuição espacial dos professores deram-se, conjuntamente, com o processo de sociabilidade e articulação docente nessas localidades. À luz da História Social da Educação, o estudo destaca o aparecimento da Liga de Professores Primários em 1912, com sede localizada na Escola Modelo Riachuelo, bem como, a presença de uma mulher como sua primeira diretora, Alzira Augusta Pires. Observou-se que a organização docente permitiu o nascimento de uma rede de sociabilidade e circulação de professores e professoras, o que resultou em algumas práticas de favorecimento entre os sujeitos que compunham esses espaços.

Palavras-chave: associativismo; educação; subúrbio; professores

\footnotetext{
1 Doutorando pelo Programa de Pós-graduação em Educação da Universidade Federal Fluminense. Professor substituto da Faculdade de Educação da Universidade Federal Fluminense. marcelogomes.dasilva@yahoo.com.br
} 




\title{
EDUCATION IN THE CARIOCA SUBURB: SOCIABILITY AND TEACHING ORGANIZATION IN THE FIRST REPUBLIC
}

\begin{abstract}
The occupation of the territory of the city of Rio de Janeiro underwent several transformations in the early twentieth century. The displacement of the poor to regions farther from the center has led to demands for transportation and schooling. The present study aims to analyze some surgical relationships in the process of educational structuring, process created to meet the demand for public education in the suburbs of Rio. In this direction, the creation of the school districts and the spatial distribution of the teachers came together with the process of sociability and teacher articulation in these localities. Based on the Social History of Education, the study highlights the emergence of the League of Primary Teachers in 1912, headquartered at the Riachuelo Model School, as well as highlights the presence of one woman as its first director, Alzira Augusta Pires. In the study it was observed that the teaching organization allowed the birth of a network of sociability and circulation of teachers, an institution that resulted in some practices of favoring among the subjects that composed those spaces.
\end{abstract}

Keywords: associativism; education; suburb; teachers 


\section{periferio}

\section{INTRODUÇÃO}

O início do século XX foi marcado por grandes transformações na cidade do Rio de Janeiro². Capital da República, a cidade passou por um processo de modernização, refletida na reestruturação ocorrida a partir das reformas urbanas. Esse processo desencadeou o reordenamento espacial da população pobre, que se viu obrigada a se deslocar para outras localidades mais afastadas da região central.

Os contextos das reformas por que passou a cidade neste período foi amplamente debatido pela historiografia, e, certamente, esse momento amplificou um movimento pela disputa do território articulado a um avanço dos interesses econômicos; se tomarmos a relação das empresas de bondes e trens na ampliação da ocupação para o subúrbio, a interesses políticos; no que tange o direcionamento dos investimentos públicos relacionado aos locais habitados pela elite da época; e por último, a ocupação do território vinculado a um projeto de modernização e civilização da cidade, com a expulsão compulsória de parte da população da região central. Neste sentido, entendemos que a oferta de escolas em determinadas localidades dialoga com essa rede de relações complexas, que marca as diferentes regiões dentro do espaço geográfico conhecido como Rio de Janeiro.

Neste aspecto, não é irrelevante marcar a localização da Liga dos Professores Primários, pois o "endereço" reflete uma categorização representativa do território que circulou em diferentes momentos. É o que aponta Nelson Fernandes (2015) sobre o conceito da categoria subúrbio. Segundo o autor, "até o fim do Império o território do Município da Corte estava dividido entre freguesias urbanas e rurais. Aquelas freguesias rurais mais próximas à cidade eram o que se considerava subúrbios" (p. 39).

\footnotetext{
2 Sobre a cidade do Rio de Janeiro, ver: ABREU, Maurício de A. Evolução urbana do Rio de Janeiro. Rio de Janeiro: Instituto Pereira Passos , 2006; LOBO, Eulália Maria Lahmeyer. História do Rio de Janeiro: do capital comercial ao capital industrial e financeiro. Rio de Janeiro: IBEMCE, 1978; CHALHOUB, Sidney. Cidade Febril: cortiços e epidemias na Corte imperial. São Paulo, Cia da Letras, 1996.
} 


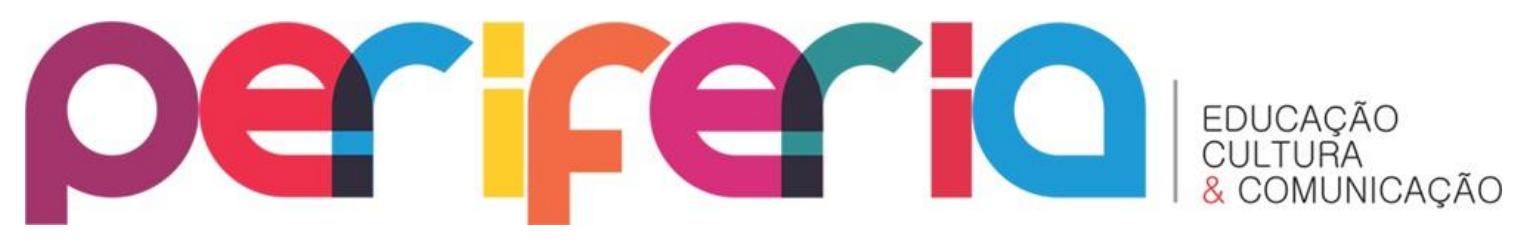

Somente no final do século XIX que realmente se desenvolve um processo de "abertura do subúrbio ao proletariado" e a partir das reformas urbanas do prefeito Pereira Passos que se detecta "a mudança espacial e social da categoria subúrbio, que deixa de ser usada na representação de todos os espaços circunvizinhos à cidade pra se fixar exclusivamente naqueles do norte e do oeste, servidos pela ferrovia" (FERNANDES, 2015, p. 58).

Algumas representações históricas sobre a cidade denominam o início dos novecentos como o período da belle époque carioca. Do mesmo modo que o conceito "subúrbio" foi se reconfigurando ao longo do tempo, Leonardo Pereira (2015) considera que a expressão, na verdade, tratou-se de uma invenção, já que havia uma "distância entre o discurso dos intelectuais e políticos que afirmavam essa imagem refinada para a cidade e a realidade experimentada pelos contemporâneos" (PEREIRA, 2015, p.108). O autor destaca ainda que após a proclamação da República houve uma desilusão com o novo regime, o que fez emergir uma nova visão, por parte de escritores e da própria imprensa, em relação à imagem da cidade, considerada também como "cidade problema".

O processo de ocupação do território da cidade pela população esteve marcado por disputas. Assim como o território, os espaços de poder, após a proclamação da República, também estavam sendo disputados por diferentes grupos. Com o novo regime abriu-se uma discussão sobre a construção de um "novo Estado", porém, os atores sociais diversificados impedia um consenso sobre a própria ideia de República. Segundo Ângela de Castro Gomes (2005), "as crises sucessivas - políticas, econômicas e sociais - que pontuam as duas primeiras décadas da República denotam a vivência do sentimento de permeabilidade do regime, e, mais que isso, de que o poder não estava ocupado" (GOMES, 2005, p. 35). Como destaca a autora, diversos atores políticos se inseriram nesse processo, principalmente em torno da camada da população denominada como "povo", no caso, os trabalhadores. O conceito de trabalhador e a ideia sobre o trabalho também estava passando por uma reconfiguração, pois o pós-abolição ainda trazia resquícios sobre os trabalhos 


\section{periferio}

manuais que precisavam ser reelaborados, já que, no Brasil "a escravidão tornara o trabalho manual um símbolo de degradação" (GOMES, 2005, p. 41).

A historiadora destaca que nesse momento havia uma disputa sobre quem seria os representantes dos trabalhadores, processo que se desencadeou no sentido de "falar aos" ou "ser a voz" destes. Neste contexto, reuniram-se sujeitos identificados com os ideais socialistas e anarquistas. A proposta de ação dos grupos em questão, apesar de divergentes em muitos aspectos, contribuiu para a organização da classe trabalhadora em associações, fato que não era novo no Brasil, mas que agora ganhava novos contornos políticos, como por exemplo, a discussão sobre cidadania. Entre os socialistas:

0 que se propunha eram formas de associações de trabalhadores, com base em ofícios, que iriam se articular e um órgão central, do qual emanariam as diretrizes políticas do movimento. O partido ou o "centro do partido" funcionaria criando uma estrutura associativa que envolveria os sindicatos de ofício e também tipos de órgãos (GOMES, 2005,p.53)

Já os anarquistas, em relação à proposta organizacional, defendiam outros mecanismos. Eles combatiam a opção dos socialistas pelo partido político e criticavam a antiga tradição associativa de bases beneficentes experimentada pelos trabalhadores. Os anarquistas propunham, visando construir um sentimento de solidariedade operária e consequentemente um sentido de pertencimento a um grupo "a atuação dentro de sindicatos, definidos como 'sindicatos de resistência'. Este novo tipo de organização se caracterizava pelo abandono das práticas assistencialistas e pela firme postura da "ação direta" ante o patronato e o Estado" (GOMES, 2005, p. 87).

Os conflitos surgidos nesse contexto de transformações, também sofreram interferências por parte do poder público, que tentava controlar alguns setores da sociedade, principalmente os trabalhadores. Se por um lado a República preconizava um "liberalismo político", por outro lado: 




O Estado brasileiro, ao mesmo tempo em que, obedecendo aos preceitos do liberalismo político, propunha-se mínimo e pouco cogitava resolver problemas na área da saúde, trabalho, previdência e lazer, proclamava constitucionalmente a liberdade de associação e criava meios de controle sobre a criação e funcionamento das então denominadas "sociedades civis" (FONSECA, 2008 p. 16).

O debate sobre associações elenca discussões sobre cidadania, direitos, o papel dessas instituições, relações entre cidadãos e Estado, temas que ainda podem ser considerados atuais, não apenas como processo histórico que tem uma origem remota, mas, principalmente, como uma questão social e política fundamental nos dias atuais (FONSECA, 2008).

Para Paulo Terra (2013) a Proclamação da República teve impacto no movimento operário e despertou anseios e expectativas de participação política. No entanto, o autor assinala que a "questão social" no Brasil era tratada como caso de polícia. Em um contexto de ausência do Estado em alguns debates, como a implantação de uma legislação trabalhista, por exemplo, coube aos próprios trabalhadores se articularem e pressionarem os poderes públicos para que suas demandas fossem atendidas e tornassem direitos. Nesse processo, as associações foram mecanismos de aglutinação e referência na organização dos trabalhadores.

Deste modo, enquanto o crescimento econômico e a urbanização mostravam-se cada vez mais acelerados, o que exigia maior regulação jurídica e controle, ao mesmo tempo, estava surgindo também, não com a mesma intensidade, diversas associações, que se voltavam principalmente para solucionar problemas em áreas que o poder público era deficiente, como a seguridade social, saúde, previdência e lazer (FONSECA, 2008).

\section{O SURGIMENTO DA LIGA DOS PROFESSORES PRIMÁRIOS}

0 ordenamento administrativo da cidade foi sendo construído ao longo dos anos, o que pode ser refletido no surgimento de diferentes órgãos, que 


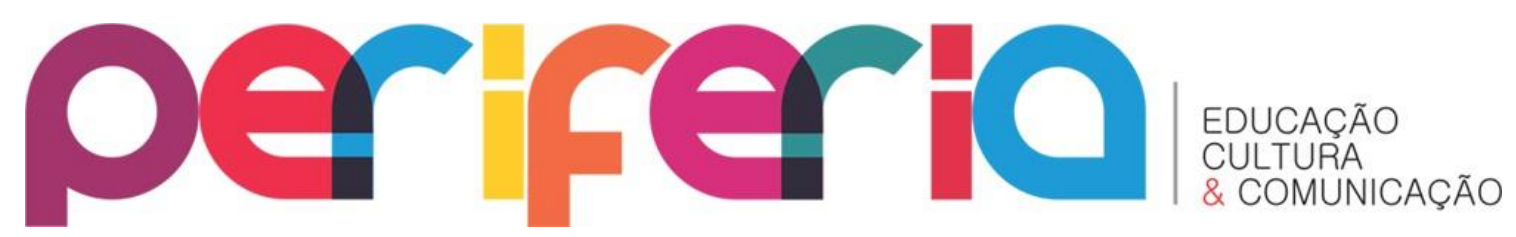

foram responsáveis por tratar de diferentes demandas. À medida que a população e a cidade cresciam o processo de escolarização também se expandia, seja pela demanda da população por instrução ou por medidas institucionais que via na instrução da população uma questão necessária ao projeto civilizacional.

Nesse sentido, podemos perceber o "mapeamento" da cidade, no que tange à instrução pública. Em 1904, o CORREIO DA MANHÃ publicou uma notícia sobre a "subdivisão do Distrito Federal em 15 circunscrições", contendo, além dos inspetores escolares, os professores e as escolas que compunham os respectivos distritos ${ }^{3}$. $09^{\circ}$ distrito, que se localizava no subúrbio carioca e possuía como inspetor o Dr. Fábio Luz, era composto por mais dezoito professores, entre eles, Alzira Augusta Pires, que foi presidente da Liga, fundada em 1912. 0 distrito possuía como limite os endereços:

Rua Flack (exclusive), rua Viuva Claudio ( a partir do Jacaré), Rua Souza Barros até a estação do Engenho Novo, Linha Ferrea, até Engenho de Dentro, rua Engenho de Dentro (inclusive) até Dias da Cruz, e rua maranhão até a serra ( 0 PAIZ, 7 de fevereiro de 1911, p.9).

A sede da Liga dos Professores Primários estava localizada precisamente na "Escola Riachuelo ( $5^{\mathrm{a}}$ feminina), Rua D. Anna Nery n. 554" 4 que tinha como regente a Professora Alzira Augusta Pires.

A Rua D. Anna Nery era margeada pela linha do trem, o que não deixa de ser um dado significativo, pois a partir de meados do século XIX houve uma expansão do sistema ferroviário na cidade do Rio de Janeiro. Aliado ao crescimento da malha ferroviária, o processo do deslocamento da população para os subúrbios sofreu influência do contexto do "bota-abaixo" no início do século XX (MIYASAKA, 2011, p. 35). No entorno da "Escola Riachuelo", na mesma rua, situava também o "Teatro Recreio Dramático Riachuelense", inaugurado em 1877. No bairro vizinho, em Engenho Novo, encontrava-se o

\footnotetext{
${ }^{3}$ CORREIO DA MANHÃ, 7 de março de 1904, p. 2.

${ }^{4}$ O PAIZ, 7 de fevereiro de 1911-p.9
} 


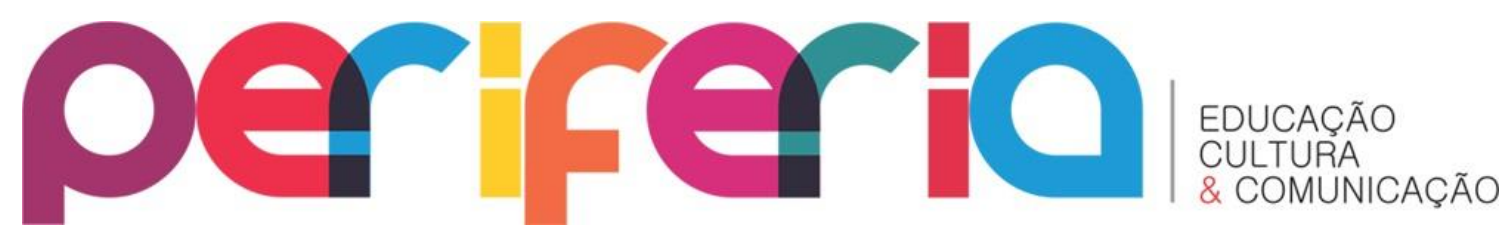

Jockey Club e o Derby Club, locais que reuniam as sociedades de turfe (FERNANDES, 2015, p. 138). Essas informações são interessantes para percebemos à circulação de diferentes sujeitos e grupos sociais diversificados compondo essa região da cidade. Um artigo publicado na Revista da Semana em 1909, e reproduzido por Nelson Fernandes (2015), nos diz que o bairro Riachuelo era um:

(...) pedaço da zona dos subúrbios cariocas que se recomenda pelo seu adiamento. 0 que lhe dá foros de aristocrático. Riachuelo está por assim dizer no mesmo plano dos nossos mais afamados bairros. É como o Engenho Novo e Todos os Santos um bairro calmo e sossegado pelo silêncio de suas ruas, onde se ostentam luxuosas construções todas circundadas de parques soberbos e pitorescos jardins. Aos sábados e à noite (...) Quase todas as ruas da pitoresca localidade são calçadas, se bem que esse calçamento date já de muitos anos, do tempo em que o Governo Municipal cuidava com empenho dos subúrbios porque estava certo de sua importância como complemento da capital (O PAIZ, 7 de fevereiro de 1911, p.9).

Ao mesmo tempo, a localização da sede da Liga no subúrbio, se destoava do que Cláudio Batalha considerou "geografia associativa", termo que intitula um trabalho no qual o autor aponta a região central do Rio de Janeiro, nos arredores do Campo de Santana, atual Praça da República, como sendo o “espaço público por excelência, o espaço da política” (BATALHA, 2009, p. 251). A afirmação é baseada na localização das sedes das várias associações existentes no início do período republicano, local que representava o centro administrativo, político e de atuação da classe trabalhadora. Houve mudanças neste cenário após a reforma Pereira Passos, entre 1903 e 1906, como aponta Batalha (2009), ocorreu uma:

segregação social e geográfica dos pobres, cada vez mais excluídos das "áreas nobres" da cidade. O aumento, em 1906, de 1,5 milhão de passageiros em relação ao precedente unicamente nas linhas suburbanas da Estrada de Ferro Central do Brasil denota o acentuado processo de ocupação dos subúrbios (Idem, p. 253.) 


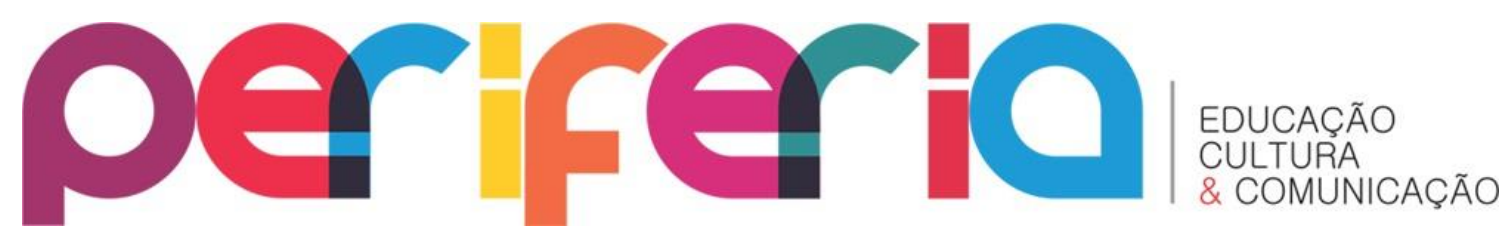

A Liga dos Professores Primários também se diferenciava por sua composição e liderança, já que apresentava como presidente da associação uma mulher: a professora Alzira Augusta Pires, fato incomum entre os cargos de direção dessas entidades na época, apesar do processo de "feminização do magistério" ter possibilitado a presença marcante das mulheres exercendo a função docente, principalmente no ensino primário. Portanto, a presença feminina na direção da Liga mostra que as professoras primárias, consideradas por Lúcia Muller como as “construtoras da nação", ocuparam “todas as brechas", exercendo uma relativa autonomia, muito maior do que as outras mulheres de sua época (MULLER, 2008)

Atualmente a profissão docente, principalmente nos anos iniciais, é majoritariamente composta por mulheres. A presença das mulheres, portanto, é uma constante na experiência educacional brasileira e contribui, consideravelmente, para a constituição da docência enquanto categoria profissional.

Entretanto, o movimento das mulheres entre a "sala de estar", do lar, para as salas de aula, foi permeado por um processo de lutas, resistências, estratégias e enfrentamentos, já que o contexto, ainda atual, é composto por uma sociedade predominantemente machista. Em relação às reivindicações salariais, por exemplo, encontramos casos de governantes usando de termos que remetem a questão de desigualdade de gênero no intuito de desqualificar as demandas de professoras, como disse Paulo Maluf: “As professoras não ganham pouco, são mal casadas". Esta estrutura parece pertencer ao tempo histórico denominado por Fernand Braudel com sendo da "longa duração", pois o discurso sobre a má remuneração relacionada ao gênero feminino era vinculado desde a Primeira República, como podemos perceber na mensagem do prefeito do Distrito Federal, Rivadávia Corrêa, lida na sessão do Conselho Municipal, em abril de 1916:

5 BRAUDEL, F. "História e Ciências Sociais. A longa duração". In: Escritos sobre a História. $2^{a}$. ed. São Paulo: Perspectiva, 1992. pp. 41-78 


\section{periferio}

A revisão dos vencimentos é uma providência que se impõe, pois a qualquer espírito desprevenido que atentar no que percebem os docentes municipais, não pode deixar de causar admiração o seu exagero, notadamente, se considerar que o elemento feminino é o que, aliás justamente, prepondera no magistério municipal e em geral as professoras não têm, como os homens, tão imperiosas responsabilidades de família (A.B.C.; 8 de abril, 1916. Pág.8. Grifos meus).

É certo que a presença feminina parece ter sido uma constante na história da profissão docente, principalmente após o chamado "processo de feminização". Parece também uma constante no decorrer da história a desqualificação por parte do poder público em relação às demandas educacionais, principalmente se essas demandas e ações partissem de mulheres:

Tem suado as estopinhas o novo administrador do município! Também, graças a sua atividade, parece que duas obras relevantes apanhará desta vez o desprezado Distrito Federal: não ficará capim nas sarjetas e no aprazível bairro da Tijuca será criada mais uma escola para meninas. A criação dessa escola tem dado água pelo bigode do infatigável coronel: mal circulou a boa nova do estabelecimento de mais uma cadeira, a Prefeitura encheu-se de senhoras que disputavam ou a regência da escola ou o cargo de adjunta. O Haussmann viu-se tonto: verificou que as professoras sem emprego eram tão abundantes como a beldroega das sarjetas. E que pessoal aquele! Candidatos masculinos são suportáveis, por mais terríveis que sejam. Mas femininos Santa Barbara! Vão desde a lábia de uns modos feiticeiros até a exigência mais absoluta e a descompostura de tome-lá-que-te-dou-eu. Professora não é brinquedo ( $\mathrm{MALHO}, 18$ de outubro de 1902, pág. 6 - Grifos meus).

"Professora não é brinquedo". Podemos imaginar a responsabilidade e o simbolismo do fato de uma mulher ocupar a direção de uma associação de professores naquele contexto. Segundo o jornal O PAIZ, na sessão "Diretoria Geral de Instrução Pública", que tratava do "expediente do dia", entre os atos do Sr. Diretor, constava a designação da professora Alzira Augusta Pires, 


\section{periferio}

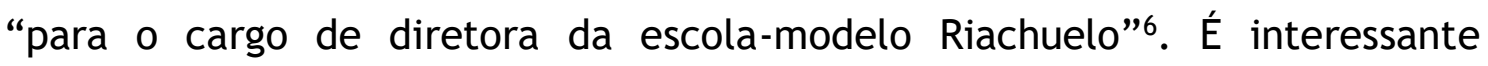
refletir sobre a relação entre a sua nomeação para diretoria da escola e a função que ocupou como primeira presidente da Liga dos Professores Primários, que funcionava no mesmo local. A professora em questão obtinha uma formação para ocupar esse espaço, era professora normalista e formou-se no ano de $1902^{7}$. No entanto, sua nomeação como "professora em escola primária do Distrito Federal" ocorreu em $1897^{8}$, cinco anos antes de se formar normalista.

O jornal GAZETA DE NOTÍCAS noticiou o evento de "Distribuição de Diplomas" das normalistas. Podemos observar a importância do acontecimento pela presença, como relatado no jornal, de autoridades na solenidade, além de ser um evento que nos permite, a partir dos discursos proferidos, refletir sobre as representações que se tinha sobre os professores e professoras. As falas indicam um ideal almejado de docente, aquilo que se esperava formar nas Escolas Normais. Como Marina Uekane (2016);

o processo de constituição da Escola Normal se deu em meio a tensões desde o momento da sua criação. Após a mudança de regime político, o movimento em torno da formação dos professores continuou acrescido de um discurso reformador voltado para a construção de uma memória que se ocupava das questões educacionais como sendo fundamentais para o desenvolvimento do país (UEKANE, 2016, p. 36).

A questão social da mulher, a representação que se tinha do seu papel, inclusive enquanto educadora, pode ser percebida no discurso do Diretor de Instrução pública. Nas palavras do Sr. Medeiros de Albuquerque, era "preciso destruir o ridículo preconceito de que o homem é que tem a força, procuremo-la no elemento feminino, porque a força não é o vigor físico, mas o carinho, o afeto que tudo alcança, que tudo domina". Nota-se a referência à figura feminina relacionada ao seu papel social, que na profissão docente

${ }^{6}$ O PAIZ, 22 de outubro de 1912, p. 9.

7 GAZETA DE NOTÍCIAS, 5 de setembro de 1902, p. 1

${ }^{8}$ GAZETA DE NOTÍCIAS, 3 de junho de 1897, p.2

${ }^{9}$ GAZETA DE NOTÍCIAS, 5 de setembro de 1902, p. 1 




marcou a relação que se esperava da mulher professora. 0 "carinho" e o "afeto" sobrepõem, ao menos no discurso proferido em uma solenidade de formatura de alunas da Escola Normal, aos preceitos da pedagogia e as discussões curriculares sobre a formação das professoras.

$\mathrm{Na}$ mesma solenidade de formatura, entre as 34 normalistas do ano de 1902, a oradora Esther Pedreira de Mello, proferiu o discurso que "findou no meio de uma revoada de palmas, sendo ela calorosamente cumprimentada pelos Srs. Presidente da República e o prefeito municipal”10.

Ao cruzar os dados da distribuição das professoras pelas escolas do município em 1904, com os nomes das normalistas que se formaram em 1902, observamos que apenas duas professoras aparecem ocupando cargos nas escolas. Entre elas, a oradora da turma, Esther Pedreira de Mello, ocupava em 1904 o cargo de Inspetora Escolar do $1^{\circ}$ Distrito. Pelo que conseguimos acompanhar a partir do cruzamento de fontes, entre a turma que se formou com a professora Alzira Pires, uma única professora ocupou o mesmo distrito que o seu. Em 1911, a professora Ana Villa Forte, que se formou em 1902, era professora na “ 5 a Escola Elementar Feminina, na Rua Dias da Cruz, n.68"11.

O jornal GAZETA DE NOTÍCIAS apresentou a lista com as "Designações de Inspetores Escolares" e a "Distribuição de Escolas"12. Baseado no decreto n. 844, de 19 de dezembro de 1901, os distritos foram distribuídos como podemos observar a seguir:

\footnotetext{
10 idem

11 O PAIZ, 1911, P. 9

${ }^{12}$ Gazeta de notícias, 6 de março de 1904, p.3
} 


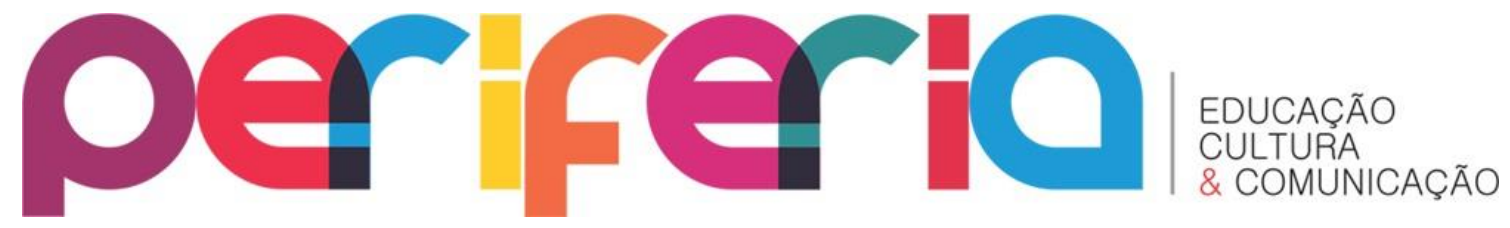

Imagem 01- Designações de Inspetores Escolares

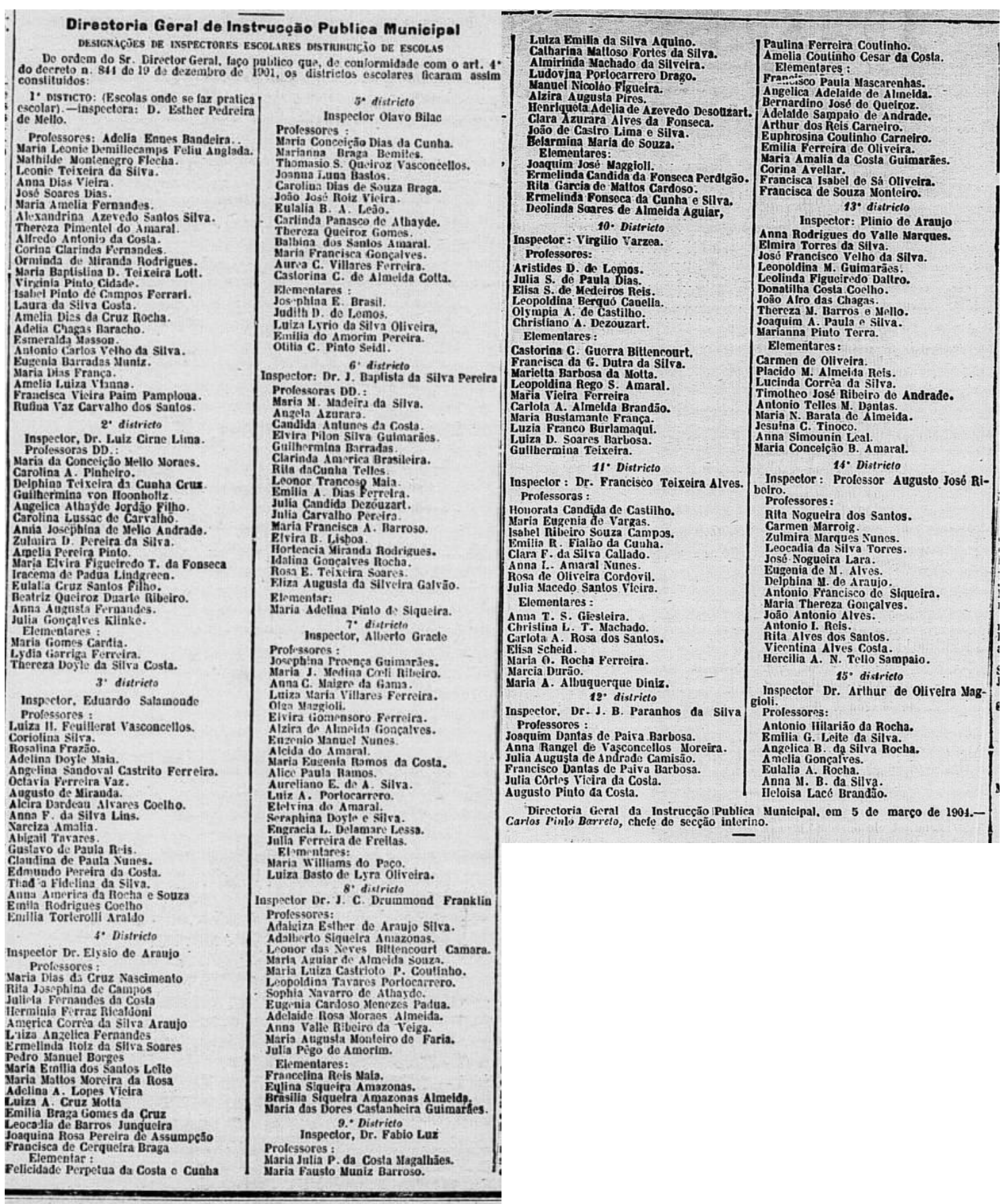

Fonte: Jornal Gazeta de notícias, 6 de março de 1904, p.3. 




É importante destacar a dinâmica das nomeações e ocupações das professoras, pois isso revela um universo que se relacionava não apenas com a competência, pois os cargos eram muitas vezes indicados, portanto, sujeitos a uma rede de sociabilidade estabelecida pelos professores. Por exemplo, o que levou a "oradora" da turma da professora Alzira Augusta Pires ser nomeada inspetora? Teria sido apenas a competência? Nesse pequeno mapeamento, vimos que de 1897, da sua primeira nomeação, até o ano de 1912, Alzira ocupou algumas escolas. Em 1907, por exemplo, estava como professora na "6 6 feminina, rua Marechal Bittencourt, n. 1"13.

A referência ao conceito de sociabilidade utilizado neste trabalho é inspirada no debate proposto por Sirinelli (2003), que ao tratar dos intelectuais, além da noção de engajamento, discorre sobre as relações estabelecidas pelos sujeitos. Segundo o autor:

Todo grupo de intelectuais organiza-se também em torno de uma sensibilidade ideológica ou cultural comum e de afinidades mais difusas, mas igualmente determinantes, que fundam uma vontade e um gosto de conviver. São estruturas de sociabilidade difíceis de apreender, mas que o historiador não pode ignorar ou subestimar (SIRINELLI, 2003, p. 248).

Alguns indícios de como a sociabilidade ou as relações que as professoras e professores estabeleciam na cidade influenciavam as nomeações e locais que iriam trabalhar, pode ser observado através das cartas trocadas entre o Inspetor Escolar, o Dr. Fábio Luz. A partir do Fundo Fábio Luz, sob a guarda do Arquivo Nacional, foi possível ter acesso a essa documentação que revela, em parte, uma prática que parecia comum à época, qual seja, o pedido de nomeações, indicações e transferências de professores e professoras.

Entre as diversas cartas que compõe o Fundo, encontram-se algumas enviadas por escritores e intelectuais, como Oswald de Andrade, Manoel Bonfim, Edgar Leuenroth etc.Os lugares que as cartas eram enviadas refletem

${ }^{13}$ O PAIZ, 8 de junho de 1907, p. 4 


\section{periferio}

a gama de relações do inspetor, pois as cartas chegavam de diferentes lugares: Uruguai, Espanha, Argentina, França e U.R.S.S. As temáticas entre as cartas recebidas tratava desde discussões sobre anarquismo à debates sobre obras literárias de diversos escritores. Além desse repertório, algumas cartas revelam as práticas do ofício de inspetor. Por exemplo, uma carta enviada por Ramiz Galvão, em 24 de março de 1915, em que dizia;

Deixo a Diretoria da Instrução sabendo de muitos companheiros e professores, grato aos Srs. Prefeitos que me honraram com a sua confiança, mas infelizmente convencido da impossibilidade de realizar desideratum completo, tamanha é a perturbação produzida pela luta dos interesses e das pretensões individuais que se opõem cada hora aos sagrados interesses da justiça da boa administração e do ensino público ${ }^{14}$.

Como destaca o Diretor da Instrução Ramiz Galvão, os "interesses" e as "pretensões individuais" interferiam diretamente sobre a "boa administração" e "ensino público". A interferência a que se refere, parece constituir-se como característica da formação do próprio Estado brasileiro, que através das conciliações conservadoras permitiram a continuidade de certos grupos no poder. Como assinala Nelson Coutinho (2014), mesmo em momentos de mudanças políticas: independência, proclamação da República, períodos pósditatoriais, o que se observa no Brasil são continuidades de certas estruturas. Portanto, mesmo possuindo um estado forte e autoritário, não significa que esse fosse imbuído de um "espírito público", pois foi cooptado por grupos que se revezavam no seu controle, atuando para a consolidação da chamada "privatização do público". Têm-se então, um Estado patrimonialista, sendo tratado por seus ocupantes, como propriedade pessoal, assim:

O elemento conteudístico mais importante dessa forma política autoritária e centralizadora de Estado é que ele sempre esteve claramente a serviço de interesses privados. 0 fato de esse Estado ter sido muito forte e de ter aparentemente se superposto à ordem privada não anula, de

${ }^{14}$ Fundo Fábio Luz, AN 007-2000 


\section{periferio}

modo algum, uma realidade fundamental: a de que toda essa força esteve sempre - em primeira ou em última instância, mais em primeira do que em última - a serviço de interesses estritamente privados (COUTINHO, 2014, p. 183).

A administração pública parece ter se constituído a partir de práticas de compadrio e dos usos das redes de sociabilidade. As cartas recebidas pelo inspetor escolar Fábio Luz, demonstram um pouco dessas práticas, é o caso da carta de Raul Maranhão, solicitando que Fábio Luz intervisse a favor de Ermelinda Pires de Oliveira para assumir o cargo de Adjunta na secretaria de educação ${ }^{15}$.São comuns pedidos desse tipo:

Venho insistir contigo pela indicação do nome de nossa boa Maria da Soledade Tristão para professora adjunta (...). A futura professora, que está aqui ao meu lado, acaba de voltar da casa do Dr. Ramiz Galvão, que a recebeu muitíssimo bem, prometeu atendê-la e apenas aguarda as tuas ordens, e assim, ela te pede e todos te pedimos que a não esqueças. José Geraldo. 1 de janeiro de $1919^{16}$.

Refletir sobre as formas de nomeações das professoras, principalmente no que se refere ao $9^{\circ}$ distrito escolar é um ponto importante para nosso trabalho, pois existia uma relação direta com o andamento da Liga dos Professores Primários, como podemos observar na descrição das "bases" da entidade. No dia 16 de junho de 1912, o jornal O PAIZ publicou as "bases" da Liga. Em seu primeiro artigo da Base II destacava-se:

Art. 1. São considerados sócios efetivos todos os professores em exercício do distrito e também o inspetor escolar.

$\S 1$. Os professores transferidos para outros distritos que quiserem continuar como associados, poderão fazê-lo, ficando encarregados da propaganda nos distritos onde trabalhares para organização de sociedades (...)

$\S$ II. Os professores particulares da zona do $9^{\circ}$ distrito poderão ser aceitos sócios, com as mesmas obrigações e direitos dos professores primários municipais.

${ }^{15}$ Fundo Fábio Luz. AN 007-2000, 06/04/1914.

16 Idem 


\section{periferio}

§ III. Os associados cuja moralidade se torna duvidosa e cujo mal proceder for verificado em inquérito aberto pela diretoria da associação, serão eliminados pela assembleia geral, por proposta da diretoria, em votação secreta, depois de apurados os documentos em que se basear a diretoria.

$\S$ IV. Transferido para o distrito professor ou adjunto desconhecido, só fará parte da Liga, depois da aprovação da diretoria.

Este dispositivo deve ser aplicado igualmente à admissão de professores particulares, cuja apresentação será feita por três sócios efetivos, professores municipais, em todo o tempo responsáveis pelo apresentado.

§V. Os professores de outros distritos poder-se hão, incorporar à associação nas mesmas condições dos professores do $9^{\circ}$ distrito em que servirem se organizarem associações congêneres (O PAIZ, 16 de junho de 1912, p. 8). (grifo nosso).

Ora, se são "considerados sócios todos os professores em exercício do distrito" é plausível pensar que a nomeação de professores interferia de alguma maneira, nas ações e desenvolvimento da entidade. Como vimos nas cartas recebidas pelo Inspetor Fábio Luz, os pedidos para que intercedesse em nomeações de professores e professoras, podemos supor que o mesmo poderia influenciar nas nomeações de docentes para o $9^{\circ}$ distrito, local de sede da Liga, que o próprio, por ser inspetor, era diretor, como observa no texto que compõe as bases da organização.

Mesmo que não houvesse nenhuma possibilidade de interferência nas nomeações dos professores para o $9^{\circ}$ Distrito, o § IV do Art. 1 das Bases da Liga garantia que "transferido para o distrito professor o adjunto desconhecido, só fará parte da Liga depois da aprovação da diretoria” ${ }^{17}$.

17 O Paiz, 16 de junho de 1912, p.8 


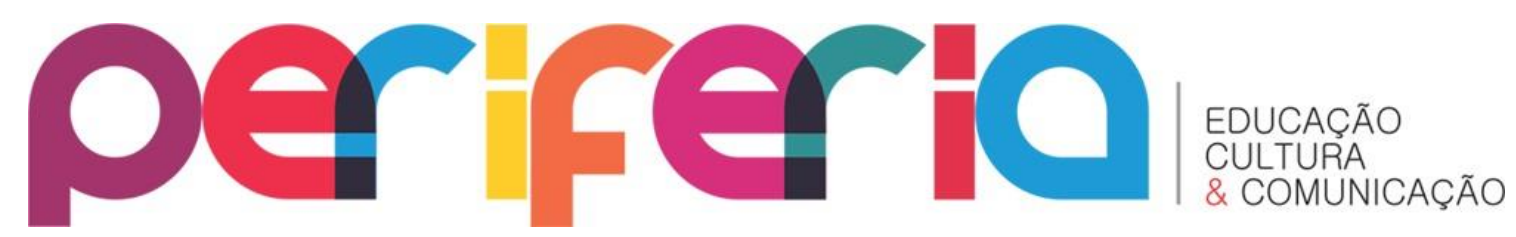

\section{CONSIDERAÇÕES FINAIS}

A partir do contexto da Primeira República, várias correntes políticas pautadas em diferentes ideais circulavam na cidade e possivelmente influenciou a criação de várias associações. É de conhecimento da historiografia que o inspetor escolar do $9^{\circ}$ Distrito, o Dr. Fábio Luz, foi um proeminente intelectual anarquista, com vasta produção literária, inclusive como articulista de diferentes jornais neste período ${ }^{18}$. Mesmo assim, pelas características apontadas por Ângela de Castro Gomes (2015) em relação à proposta organizativa dos socialistas e anarquistas, não é possível apontar ou definir qual o direcionamento ideológico da Liga. Em primeiro lugar é preciso ressaltar a condição de identidade do professor, que naquele momento também estava se constituindo, tal qual a categoria "trabalhador".

Observamos algumas semelhanças entre as associações docentes e de trabalhadores, como a organização de bibliotecas, por exemplo. Mas o importante é destacarmos a tentativa de organização dos professores e, a partir disso, tentar perceber como que esse processo ajudou a formar a própria ideia do que representava ser professor. A principal finalidade da Liga dos Professores Primários estava exposta na sua "Base I", que dizia:

A associação tem por fim reunir solidariamente os professores
do distrito em uma ação conjunta e amigável em bem da
instrução pública. Esta ação se manifestará pela organização
de uma biblioteca; pela instituição de palestras pedagógicas;
pelo auxílio mutuo prestado na execução dos programas, e nos
esclarecimentos que os mais práticos, mais antigos e mais
traquejados no serviço possam prestar aos seus companheiros;
pelo acordo na organização da [excripituração] escolar; pela
melhor interpretação dada aos programas de ensino; pela boa
vontade na realização e no funcionamento das caixas
escolares e na distribuição dos benefícios; pelo auxílio

${ }^{18}$ Ver: CUNHA, Raphael R. da Silva. Fábio Luz e a educação anarquista. Pedagogia Libertária e experiências educacionais anarquistas no Brasil (1900 - 1920). Dissertação (Mestrado em Educação) - Faculdade de Educação, Universidade Federal Fluminense, Niterói, 2013. CAMPOS, Andreia da S. Laucas. Fábio Luz e a Pedagogia Libertária: traços da educação anarquista no Rio de Janeiro (1898-1938). Dissertação (Mestrado em Educação) - Faculdade de Educação, Universidade do Estado do Rio de Janeiro, Rio de Janeiro, 2007. 


\section{periferio}

prestado aos mais necessitados, não só auxilio moral como também material (O PAIZ, 16 de junho de 1912, p.8).

Nota-se que a intenção da organização não ser restringia apenas "aos professores", mas envolvia questões estruturais que envolviam setores da sociedade, os alunos, por exemplo. A “ação conjunta e amigável em bem da instrução pública" remetia ao fornecimento não apenas de "auxílio moral", mas também “material”. Nas bases também já se definia a relação com a Diretoria Geral de Instrução, “afim de lhe ser concedida, em uma escola do distrito, sala para seu funcionamento, enquanto não tiver sede própria”.

O surgimento das associações precisa ser articulado com o seu contexto, pois como alertou Marc Bloch “nunca se explica plenamente um fenômeno histórico fora do estudo do seu momento" (BLOCH, 2002, p.60). No entanto, seguindo os preceitos do mesmo autor, não podemos incorrer no erro do "ídolo das origens”, ou seja, achar que "o começo basta para explicar”.

Mac Cord e Batalha apontam que o associativismo remete para debates angariados pelo iluminismo, onde a noção de indivíduo foi construída, assim ganhava espaço "a defesa da vida pública, a luta pela participação social mais ampla, o desejo pela ampliação da vida política strictu sensu e os combates pela carreira aberta ao talento" (MAC BLOCH; BATALHA, p.11).

Neste sentido, é interessante refletir sobre os motivos que levaram os professores / trabalhadores a se organizarem. Alguns trabalhos indicam caminhos interpretativos para compreender os processos de surgimento e desaparecimento das associações ao longo do tempo. Daniel Lemos, em estudo sobre o movimento associativista docente na segunda metade do século XIX no Rio de Janeiro, percebeu que a atuação dos professores em movimentos reivindicatórios não é algo estranho ou vindo de fora da prática docente, mas que dela faz parte (LEMOS, 2006).

Denice Catani, ao analisar Associação Beneficente do Professorado de São Paulo, compreende que as associações ajudam a criar um "domínio de atuação" por parte dos professores, o que contribui para pensarmos as 


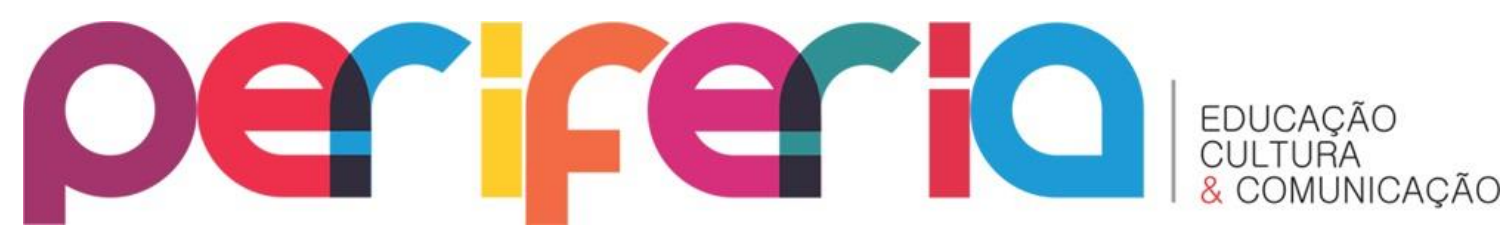

associações também como espaços de experiência, que corroboram para a própria formação da categoria docente (CATANI, 2003).

Neste caso, o conceito de experiência, cunhado por Thompson, atua como um caminho para a análise histórica, ao levar em consideração nos processos às relações humanas, seus desejos, vontades e cultura:

as pessoas não experimentam sua própria experiência apenas como ideias, no âmbito do pensamento e de seus procedimentos, ou (como supõem alguns praticantes teóricos) como instinto proletário etc. Elas também experimentam sua experiência como sentimento e lidam com esses sentimentos na cultura, como normas, obrigações familiares e de parentesco, e reciprocidades, como valores ou (através de formas mais elaboradas) na arte ou nas conviccõos religiosas. [...] Isso significa, exatamente, não propor que a "moral" seja uma "relação autônoma" da escolha e da vontade humanas, que surge independente do processo histórico. ... Pelo contrário, significa dizer que toda contradição é um conflito de valor, tanto quanto um conflito de interesse; que cada "necessidade" há um afeto, ou "vontade", a caminho de se transformar num dever (e vice-versa); que toda luta de classe é ao mesmo tempo uma luta acerca de valores (THOMPSON, 1981, p. 189-190).

Para o autor, não existe uma autonomia total, mas, o homem não se coloca como um ser passivo nesse processo, pois ele vive, experimenta, sente e age a partir das suas condições, se constituindo também a partir das suas relações, que podem ser entendidas como sendo "pedagógicas".

Cláudia Viscardi, ao analisar as associações mutualistas, destaca os conceitos trazidos à história "pelas mãos da antropologia e da sociologia, como os de identidade, sociabilidade, cultura cívica, opinião pública, esfera pública e cidadania" (VISCARDI, 2014, p. 192). Para a autora, o surgimento das associações está inserido em um processo de mobilização social que marcou o movimento de modernização do país. Aponta ainda, algumas práticas comuns àquelas associações que contribui para compreendermos 0 sentido que cada grupo constrói para se organizarem, por exemplo, a 


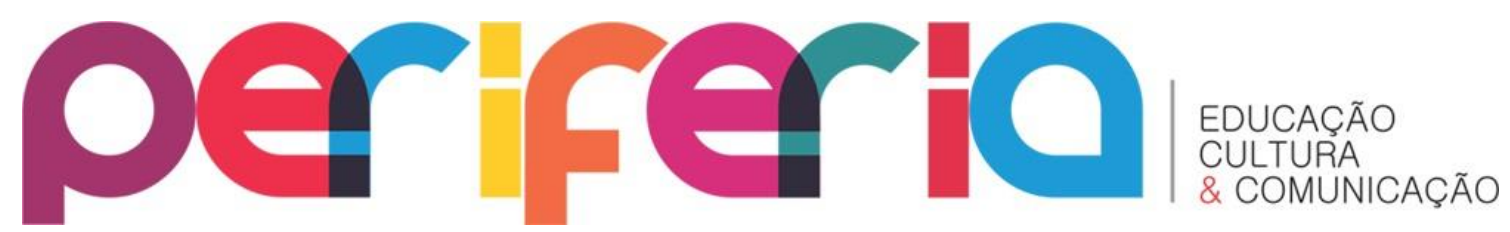

importância dada à educação dos sócios e seus descendentes, além de assinalar que:

A retórica fraternal, o uso da metáfora da família, o apelo à ajuda mútua e o reforço da ideia de que o altruísmo é preferível ao individualismo compunham parte do universo cognitivo, não só das mutuais, mas das irmandades, das guildas, das corporações, das lojas maçônicas e de outras associações que faziam parte do vasto universo associativo ao longo do tempo (VISCARDI, 2014, p. 210).

O movimento analítico de refletir sobre os motivos e razões que incentivaram a organização das diferentes categorias de trabalhadores segue a linha de pensar nas possíveis "vantagens" dos associados. Neste sentido, pode-se refletir sobre o caráter excludente das associações, ou seja, o não beneficiamento dos não sócios.

Essa relação, no entanto, leva em consideração apenas a questão da organização pela necessidade, mas, segundo Aldrin Castelluci, os trabalhadores também podem se organizar tendo como incentivo a “construção de identidades”, o que faz emergir, consequentemente, uma visibilidade pública (CASTELLUCI, 2014, p.48).

\section{REFERÊNCIAS}

BATALHA, C. H.M. A geografia associativa: associações operárias, protesto e espaço urbano no Rio de Janeiro da Primeira República. In: AZEVEDO, E.; CANO, J.; CUNHA, M. C. P.; CHALHOUB, S. (Orgs). Trabalhadores na Cidade: cotidiano e cultura no Rio de Janeiro e em São Paulo, séculos XIX e XX. Campinas, SP: Editora da Unicamp, 2009.

BLOCH, M. Apologia da história, ou, O ofício do historiador. Rio de Janeiro: Jorge Zahar Ed., 2001.

CASTELLUCCI, A. A. S. O associativismo mutualista na formação da classe operária em Salvador (1832-1930). In: MAC CORD, M.; BATALHA, C. H. M. (Orgs.) Organizar e Proteger: trabalhadores, associações e mutualismo no Brasil (séculos XIX e XX). Campinas, SP: Editora da Unicamp, 2014. 


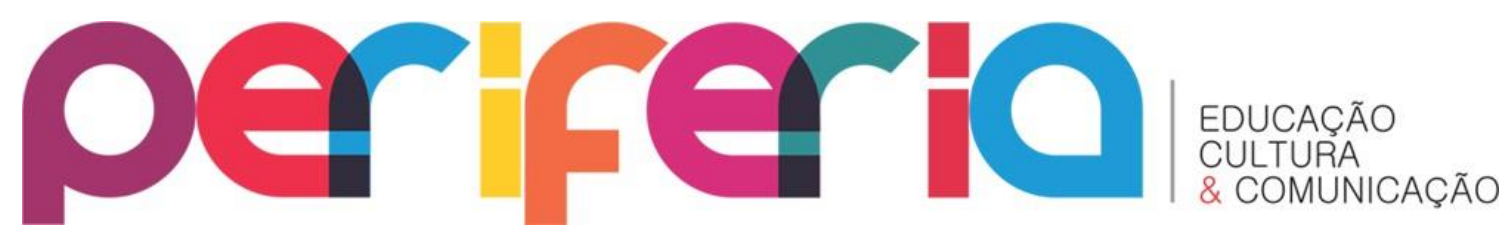

CATANI, D. B. Educadores à meia luz: um estudo sobre a revista de Ensino da Associação Beneficente do Professorado Público de São Paulo. Bragança Paulista: EDUSF, 2003. Estudos CDAPH. Série Historiografia.

FERNANDES, N. da N. O rapto ideológico da categoria subúrbio. Rio de Janeiro: Apicuri, 2015

FONSECA, V. M. M. da. No gozo dos direitos civis: associativismo no Rio de Janeiro, 1903-1916. Rio de Janeiro/Niterói, Arquivo Nacional/Muiraquitã, 2008.

GOMES, Â. de C. A invenção do Trabalhismo. Rio de Janeiro: Editora FGV, 2005.

LEMOS, D. C. A. O discurso da Ordem: a constituição do campo docente na Corte Imperial. 2006. 188f. Dissertação (Mestrado em Educação). Programa de Pós Graduação em Educação, Universidade do Estado do Rio de Janeiro. Rio de Janeiro: 2006.

MAC CORD, M.; BATALHA, C. H. M. (Orgs.) Organizar e Proteger: trabalhadores, associações e mutualismo no Brasil (séculos XIX e XX). Campinas, SP: Editora da Unicamp, 2014.

MIYASAKA, C. R. Viver nos subúrbios: a experiência dos trabalhadores de Inhaúma (Rio de Janeiro, 1890-1910). Rio de Janeiro: Secretaria Municipal de Cultura, Arquivo Geral da Cidade do Rio de Janeiro, 2011.

MULLER, M. L. R. A Cor da escola: imagens da primeira república. Cuiabá: EDUFMT/Entrelinhas, 2008.

PEREIRA, L. A. de M. Uma Capital toda prosa: a invenção da belle epoque carioca. In: MATTOS, I.; SANTOS; J.; ANTUNES, R. (OrgS.). Rio de Janeiro: histórias concisas de uma cidade de 450 anos. Secretaria Municipal de Educação. Rio de Janeiro: SME, 2015.

SIRINELLI, J. F. Os intelectuais. In: RÉMOND, R. (Org.). Por uma história política. Rio de Janeiro. FGV. 2003.

TERRA, P. C. Cidadania e trabalhadores: cocheiros e carroceiros no Rio de Janeiro (1870 - 1906). Rio de Janeiro: Prefeitura do Rio/Casa Civil/ Arquivo Geral da Cidade do Rio de Janeiro, 2013.

THOMPSON, E. P. A Miséria da Teoria ou Um Planetário de Erros. Trad.: Waltensir Dutra. Rio de Janeiro: Zahar Editores, 1981. 


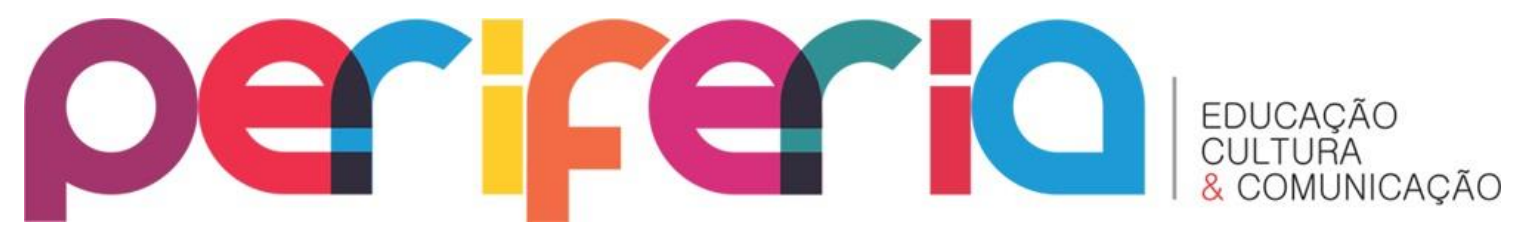

- A formação da classe operária inglesa: a árvore da liberdade. Rio de Janeiro: Paz e Terra, 1987, v. 1.

VISCARDI, C. M. R. 0 ethos mutualista: valores, costumes e festividades. In: MAC CORD, M.; BATALHA, C. H. M. (Orgs.) Organizar e Proteger: trabalhadores, associações e mutualismo no Brasil (séculos XIX e XX). Campinas, SP: Editora da Unicamp, 2014. 